\title{
Correlation of Helicobacter pylori infections in patients of dyspepsia with or without ulcer with endoscopic findings
}

\author{
Singh TSK ${ }^{1}$, Dhakal OP ${ }^{2}$, Gautam D ${ }^{3}$, Khandelwal B ${ }^{4}$, Dhakal Mona ${ }^{5}$, Lepcha OT ${ }^{6}$, Bhandari $D^{7}$ \\ ${ }^{1}$ Dr T.S.K Singh, Department of Microbiology, ${ }^{2}$ Dr O P Dhakal, Department of Medicine, ${ }^{3}$ Mr Gautam D, Department \\ of Microbiology, ${ }^{4}$ Dr B Khandelwal, Department of Medicine. ${ }^{5}$ Dr Mona Dhakal, Department of Medicine, ${ }^{6} \mathrm{Mr} \mathrm{O} \mathrm{T}$ \\ Lepcha, Department of Microbiology, ${ }^{7} \mathrm{Mr}$ D Bhandari, Department of Microbiology. All are affiliated with Sikkim \\ Manipal Institute of Medical Sciences, Gangtok, Sikkim
}

Address for Correspondence: Dr. O P Dhakal, Professor. Department of Medicine, Sikkim Manipal Institute of Medical Sciences, $5^{\text {th }}$ Mile Tadong, Gangtok, Sikkim, India

\begin{abstract}
Introduction: Since the discovery of H. pylori in 1983, the diagnosis and treatment of upper gastrointestinal diseases have changed greatly. A higher risk of the development of gastric cancer has been reported in subjects with positive serologic tests for H. pylori. Aims: Isolation of Helicobacter pylori from dyspeptic patient with or without ulcer and its correlation with endoscopic findings. Settings and Design: Prospective cross sectional study. Methods and Material: The study was conducted in the Department of Microbiology, SMIMS, Tadong, Gangtok for a period of 1 year (01.05.2013 - 30.04.2014) with patients with symptoms of dyspepsia. The parameters of investigation included upper gastrointestinal endoscopy, rapid urease test, Gram smear examination and isolation \& identification of $\mathrm{H}$. pylori by cultural technique. Results: Out of 50 patients, 32(64\%) were positive for H. pylori by any of the three parameters. Of these, $26(52 \%)$ were positive by RUT, 16(32\%) by direct Gram stained smears, and 9(18\%) by culture. Out of 50 samples, 9 (18\%) were positive by both RUT and direct Gram smear microscopy, 7 (14\%) by both RUT and culture, 9 $(18 \%)$ by both direct Gram smear microscopy and culture and $7(14 \%)$ by all the three methods. Discussion: The results revealed that the RUT should not be a sole criterion for diagnosis of dyspepsia associated by H. pylori. Culture is probably the most difficult approach to the diagnosis of H. pylori, however, it is considered as gold standard, highly specific and also antibiotic sensitivity can be detected. Conclusions: Among the endoscopic findings, esophagitis cases revealed $100 \%$ positive result by all the three parameters, while duodenitis, antroduodenitis and antral gastritis showed, $57 \%, 50 \%$ and $38.4 \%$ positive result by any of the three parameters. Considering our results it reveals that there is much correlation between esophagitis and $\mathrm{H}$. pylori infection.
\end{abstract}

Key-words: Dyspepsia, Endoscopy, Helicobacter pylori, Peptic ulcer, Rapid urease test

\section{Introduction}

Since the discovery of $\mathrm{H}$. pylori in 1983, the diagnosis and treatment of upper gastrointestinal diseases have changed greatly [1]. A higher risk of the development of gastric cancer has been reported in subjects with positive serologic tests for $\mathrm{H}$. pylori $[2,3,4]$. Many of the recent studies have found $\mathrm{H}$. pylori to be associated with gastric cancer [5,6,7]. More than two and a half decade since its discovery, H. pylori has remained to be the major cause of peptic ulcer and gastritis [8,9]. Epidemiological and clinicopathological studies have

\footnotetext{
Manuscript received: $2^{\text {nd }}$ March 2016

Reviewed: $13^{\text {th }}$ March 2016

Author Corrected: $22^{\text {nd }}$ M

Accepted for Publication: $5^{\text {th }}$ April 2016
}

revealed convincing evidence that the organism is implicated in acute superficial gastritis, chronic atrophic gastritis, gastric carcinoma and MALT associated lymphoma[10]. H. pylori are a type of intestinal Gram negative bacteria that cause the majority of ulcers in the stomach and duodenum.

Human gastric mucus is thought to be the sole source of H.pylori. The exact source and mechanism of transmission of H.pylori are not completely understood. The source may be from human or animal and environment such as polluted water and contaminated vegetables and fruits and the transmission may be fecal 
- oral and unclean vegetables and water. In order to understand the etiology of peptic ulcer and non ulcer dyspepsia in Sikkim, this research study was conducted. Early diagnosis and detection of $\mathrm{H}$. pylori infection associated with peptic ulcer will help not only in the eradication of infection but also in preventing the development of gastric carcinoma.

\section{Aims \\ Isolation of Helicobacter pylori from dyspeptic patient with or without ulcer and its correlation with endoscopic findings.}

\section{Settings and Design}

Prospective cross sectional study

\section{Methods and Material}

The study was conducted in the Department of Microbiology, SMIMS, Tadong, Gangtok for a period of 1 year (01.05.2013 - 30.04.2014). Patients with symptoms of dyspepsia presented as outpatients or inpatients in the Department of Medicine, Central Referral Hospital, were included in the study after obtaining a written informed consent and following the ICMR's Ethical guidelines for biomedical research on human participants (2006). A total of 50 patients were included in the study out of which $28(56 \%)$ were male and $22(44 \%)$ were female between the age group of 2279 years. The parameters of investigation included upper gastrointestinal endoscopy, rapid urease test, Gram smear examination and isolation \& identification of H. pylori by cultural technique. Patients with symptoms of dyspepsia above the age of 18 years were included in the study and non consenting patients, pregnant women, patients who are/were on H. Pylori eradication regime and patients with known cases of gastric carcinoma were excluded from the study.The diagnosis and classification of dyspepsia were done according to Rome III Committee criteria. A proforma written in English (translated in the local language) indicating patients' particulars, history with open ended questionnaires was used to collect information for data analysis.
All the patients were subjected to detailed history taking including history of alcoholism, smoking, use of non steroidal analgesics \& steroids and dietary factors. Two endoscopic biopsy specimens were taken by expert Gastroenterologist in a sterile container. One specimen was used for Rapid Urease Test (RUT), supplied by, Halifax Research Laboratory, Kolkata and the second specimen was transported to the Microbiology laboratory in a sterile saline solution within 30 minutes of collection. Pre-treatment of the biopsy specimen was done by washing in a sterile saline solution so as to improve the isolation of $\mathrm{H}$. Pylori. The biopsy sample was then grinded using electrical tissue homogenizer. The grinded specimen was inoculated in a selective culture medium; Columbia agar (Hi media) with Hemin (Hi media), Campylobacter growth supplement (Hi media) and Campylobacter selective supplement (Hi media) and non selective medium; Chocolate agar with Columbia agar, $1 \%$ vitox and 5\% sheep blood. Smear was also prepared on a clean new slide from the grinded biopsy specimen for microscopy examination by Gram stain to observe the presence of short, curved or ' $S$ ' shaped Gram negative bacilli. The culture plate was incubated at $37^{\circ} \mathrm{C}$ in a microaerophilic environment in a Genbox jar (Biomeriux) using Genbox Microaer pack (Biomeriux) for 10 days. The culture plate was observed after 48 hours, 3 days, 4 days, 7 days and 10 days for the appearance of growth if any and the Microaer pack was replaced with new one after each observation. The sample was declared culture negative if there was no growth after 10 days of incubation. From the positive culture plate suspected colonies of $\mathrm{H}$. pylori was identified by colony morphology, Gram stain, oxidase disc test (Himedia), catalase test, growth at $42^{\circ} \mathrm{C}$, hydrolysis of hippurate $(1.6 \mathrm{mg} /$ disc, Himedia), $\mathrm{H} 2 \mathrm{~S}$ production in TSI agar medium, reduction of nitrate to nitrite, susceptibility to cephalothin disc (30mcg/disc, Himedia), susceptibilty to nalidixic acid disc (30mcg/disc, Himedia)

Statistical analysis used: Clinical presentation in terms of number of patients with each symptom in $\mathrm{H}$. pylori positive and $\mathrm{H}$. pylori negative group was compared using chi-square test.

\section{Results}

Out of 50 patients, 32 (64\%) were positive for H. pylori by any of the three parameters used for the diagnosis of dyspepsia associated with H. pylori infections. Of these, Twenty six (52\%) were positive by RUT, 16 (32\%) by direct Gram stained smears, and $9(18 \%)$ by culture. While comparing all the three methods with each other, out of 50 samples, $9(18 \%)$ were positive by both RUT and direct Gram smear microscopy, 7 (14\%) by both RUT and culture, 9 (18\%) by both direct Gram smear microscopy and culture and $7(14 \%)$ by all the three methods (Table I). In 24 RUT negative 
cases, 7(29.1\%) were positive by direct Gram smear and 2(8.3\%) by culture. The upper gastrointestinal endoscopy of 50 patients revealed that, 7(14\%), 13(26\%), 2(4\%) and 28(56\%) patients were having duodenitis, antral gastritis, esophagitis and antro-duodenitis, respectively. Of the 7 duodenitis cases, 4(57.1\%) were RUT positive but negative by direct Gram smear and culture. Out of 13 antral gastritis cases, 5(38.4\%) were positive by RUT but all were negative by direct Gram smear and culture. Two esophagitis cases were positive by RUT, direct Gram smear and culture. In 28 antro-duodenitis cases, $14(50 \%)$ were RUT and direct Gram smear positive and 7(25\%) were culture positive (Table II).

Table-I: Comparison between direct Gram smear, RUT and culture positive results.

\begin{tabular}{|l|l|l|l|l|l|}
\hline \multicolumn{2}{|l|}{ Total sample processed: 50 } & \multicolumn{2}{l|}{ Culture positive } \\
\hline \multicolumn{2}{|l|}{ Direct Gram smear positive } & RUT positive & \multicolumn{2}{l|}{$9(18 \%)$} \\
\hline $16(32 \%)$ & Culture & Direct Gram & Culture & Direct Gram \\
RUT & Positive & $9(37 \%)$ & $7(27 \%)$ & $9(100 \%)$ & $\begin{array}{l}\text { RUT } \\
\text { Positive }\end{array}$ \\
\hline $9(60 \%)$ & $9(60 \%)$ & $78 \%)$ & $7(78$ positive \\
\hline
\end{tabular}

Table-II: Comparison of endoscopic findings with RUT, direct smear and culture results:

\begin{tabular}{|l|l|l|l|l|}
\hline & $\begin{array}{l}\text { Duodenitis } \\
\mathbf{7 ( 1 4 \% )}\end{array}$ & $\begin{array}{l}\text { Antral } \\
\text { gastritis } \\
\mathbf{1 3}(\mathbf{2 6 \%})\end{array}$ & $\begin{array}{l}\text { Esophagitis } \\
\mathbf{2}(\mathbf{4 \%})\end{array}$ & $\begin{array}{l}\text { Antro-duodenitis } \\
\mathbf{2 8}(\mathbf{5 6 \%})\end{array}$ \\
\hline RUT positive & $4(57.1 \%)$ & $5(38.4 \%)$ & $2(100 \%)$ & $14(50 \%)$ \\
\hline Direct Gram smear positive & $0(0.00 \%)$ & $0(0.00 \%)$ & $2(100 \%)$ & $14(50 \%)$ \\
\hline Culture positive & $0(0.00 \%)$ & $0(0.00 \%)$ & $2(100 \%)$ & $7(25 \%)$ \\
\hline
\end{tabular}

Table-III: Comparison of heart burn with RUT, direct Gram smear and culture results

\begin{tabular}{|l|l|l|l|}
\hline & $\begin{array}{l}\text { Heart burn present: } \\
\text { 40 cases }\end{array}$ & $\begin{array}{l}\text { Heart burn absent: } \\
\text { 10 cases }\end{array}$ & P value \\
\hline RUT positive & $21(52.5 \%)$ & $5(50 \%)$ & 0.88 \\
\hline RUT negative & $19(47.5 \%)$ & $5(50 \%)$ & \multirow{2}{*}{0.095} \\
\hline Direct Gram smear positive & $15(37.5 \%)$ & $1(10 \%)$ & \multirow{2}{*}{0.46} \\
\hline Direct Gram smear negative & $25(62.5 \%)$ & $9(90 \%)$ & \\
\hline Culture positive & $8(20 \%)$ & $9(10 \%)$ & $9(90 \%)$ \\
\hline Culture negative & $32(80 \%)$ & & \\
\hline
\end{tabular}

Table-IV: Comparison of postprandial fullness with RUT, direct smear and culture results

\begin{tabular}{|l|l|l|l|}
\hline & $\begin{array}{l}\text { Postprandial fullness } \\
\text { present: 26 cases }\end{array}$ & $\begin{array}{l}\text { Postprandial fullness } \\
\text { absent: 24 Cases }\end{array}$ & P value \\
\hline RUT positive & $15(57.6 \%)$ & $11(45.8 \%)$ & 0.4 \\
\hline RUT negative & $11(42.3 \%)$ & $13(54.1 \%)$ & \multirow{2}{*0.025}{} \\
\hline Direct Gram smear positive & $12(46.1 \%)$ & $4(16.6 \%)$ & 0.33 \\
\hline Direct Gram smear negative & $14(53.8 \%)$ & $20(83.3 \%)$ & $3(12.5 \%)$ \\
\hline Culture positive & $6(23.07 \%)$ & $21(87.5 \%)$ & \\
\hline Culture negative & $20(76.9 \%)$ & & \\
\hline
\end{tabular}


Table-V: Comparison of postprandial nausea with RUT, direct Gram smear and culture results.

\begin{tabular}{|l|l|l|l|}
\hline & $\begin{array}{l}\text { Postprandial nausea } \\
\text { present: 21 cases }\end{array}$ & $\begin{array}{l}\text { Postprandial nausea } \\
\text { absent: 29 cases }\end{array}$ & \multirow{2}{*}{0.96} \\
\hline RUT positive & $11(45.8 \%)$ & $15(51.7 \%)$ & \\
\hline RUT negative & $10(47.6 \%)$ & $14(48.2 \%)$ & 0.3 \\
\cline { 1 - 2 } Direct Gram smear positive & $5(23.8 \%)$ & $11(37.9 \%)$ & \multirow{2}{*}{0.57} \\
\cline { 1 - 2 } Direct Gram smear negative & $16(76.1 \%)$ & $6(20.6 \%)$ & \\
\hline Culture positive & $3(14.2 \%)$ & $23(79.3 \%)$ & \\
\hline
\end{tabular}

Table-VI: Comparison of vomiting with RUT, direct Gram smear and culture

\begin{tabular}{|c|c|c|c|}
\hline & $\begin{array}{l}\text { Vomiting present: } \\
24 \text { cases }\end{array}$ & $\begin{array}{l}\text { Vomiting absent: } \\
26 \text { cases }\end{array}$ & $P$ value \\
\hline RUT positive & $14(58.3 \%)$ & $12(46.1 \%)$ & \multirow[t]{2}{*}{0.39} \\
\hline RUT negative & $10(41.6 \%)$ & $14(53.8 \%)$ & \\
\hline Direct Gram smear positive & $10(41.6 \%)$ & $6(23.07 \%)$ & \multirow[t]{2}{*}{0.16} \\
\hline Direct Gram smear negative & $14(58.3 \%)$ & $20(76.9 \%)$ & \\
\hline Culture positive & $7(29.1 \%)$ & $2(7.6 \%)$ & \multirow[t]{2}{*}{0.04} \\
\hline Culture negative & $17(70.8 \%)$ & $24(92.3 \%)$ & \\
\hline
\end{tabular}

Clinically, all the patients presented with abdominal pain. Among them 26(52\%), 16(32\%) and 9(18\%) were positive by RUT, direct Gram smear and culture, respectively.

Heart burn is a frequent association in dyspeptic patients. Out of 40 patients with heart burn 21(52.5\%), 15(37.5\%) and $8(20 \%)$ were positive by RUT, direct Gram smear and culture, respectively. In patients without heart burn, had positivity of $5(50 \%), 1(10 \%)$ and $1(10 \%)$ by RUT, direct Gram smear and culture, respectively. There was no statistically significant association between heart burn and positive tests for $\mathrm{H}$. pylori (Table III).

Of the 50 patients, 26 cases complained postprandial fullness while 24 did not have. Out of 24 patients with postprandial fullness, $15(57.6 \%), 12(46.1 \%)$ and $6(23.07 \%)$ were positive by RUT, direct Gram smear and culture, respectively. Of the 24 patients without postprandial fullness, 11(45.8\%), 4(16.6\%) and 3(12.5\%) were positive by RUT, direct Gram smear and culture, respectively. The positivity by direct Gram smear microscopy between patients with and without postprandial fullness was statistically significant $(\mathrm{P}<0.05)$ (Table IV).

On comparing postprandial nausea with $\mathrm{H}$. pylori positive, it was observed that out of 21 patients of dyspepsia with postprandial nausea, $11(45.8 \%), 5(23.8 \%)$ and $3(14.2 \%)$ were positive by RUT, direct Gram smear and culture, respectively. This was not statistically significant as 29 patients who did not have postprandial nausea also were positive in $15(51.7 \%), 11(37.9 \%)$ and 6(20.6\%) by RUT, direct Gram smear and culture, respectively (Table V).

Vomiting as an associated symptom was present in 24 patients only. Of the 24 patients with vomiting 14(58.3\%), $10(41.6 \%)$ and $7(29.1 \%)$ were positive by RUT, direct Gram smear and culture, respectively. Twenty six patients did not have vomiting, but showed positivity in 12(46.1\%), 6(23.07\%) and 2(7.6\%) by RUT, direct Gram smear and culture, respectively. Culture positivity in the two groups shows statistically significant result $(\mathrm{P}<0.05)$ (Table VI). 


\section{Discussion}

Recently, H. pylori have been increasingly reported as the cause of duodenal ulcer, dyspepsia and gastritis [11]. The association of H. pylori has been reported in duodenal ulcer disease from different parts of the world including India $[12,13]$. In our study out to 50 patients, 26(52\%) were positive by RUT, 16(32\%) were positive by direct Gram smear microscopy by and 9(18\%) by culture. According to Arora et al, out of 75 cases of dyspepsia, RUT was positive in 54(72\%), culture in $21(28 \%)$ and direct Gram stained smear in $15(20 \%)$ cases[14]. This was quite comparable to our findings. In contrast S. Sengupta et al. found a high positivity rate of $96 \%, 84 \%$ and $68 \%$ for RUT, direct Gram smear and culture, respectively [15].

In this study, out of 24 RUT negative cases, 7(29.1\%) were positive by direct Gram smear and 2(8.3\%) positive by culture. The result revealed that the RUT should not be a sole criterion for diagnosis of dyspepsia associated by $\mathrm{H}$. pylori.

Culture is probably the most difficult approach to the diagnosis of $\mathrm{H}$. pylori, however, it is considered as gold standard, highly specific and also antibiotic sensitivity can be detected [16]. In one study in Punjab, India, $\mathrm{H}$. pylori was isolated from $28 \%$ cases while smear was positive only in $20 \%$ cases [4]. Similar findings were reported by other workers in India [17], though some have reported higher results $[18,19]$. This low isolation rate may be due to its patchy distribution in gastric mucosa, fastidious nature, mucosal atrophy [20], intestinal metaplasia (in stomach), administration of antibiotics (due to some other infections)[17] and proton pump inhibitors [21].

Among the endoscopic findings, esophagitis cases revealed $100 \%$ positive result by all the three parameters, while deodenitis, antroduodenitis and antral gastritis shows, $57 \%, 50 \%$ and $38.4 \%$ positive result by any of the three parameters used for diagnosis of $\mathrm{H}$. pylori infection. Considering our results it reveals that there is much correlation between esophagitis and $\mathrm{H}$. pylori infection.

As considering our findings, we recommend that a combination of RUT with Gram smear and or culture should be performed to diagnose a case of dyspepsia associated with Helicobacter pylori.

\section{Conclusions}

Among the endoscopic findings, esophagitis cases revealed $100 \%$ positive result by all the three parameters, while duodenitis, antroduodenitis and antral gastritis shows, $57 \%, 50 \%$ and $38.4 \%$ positive result by any of the three parameters used for diagnosis of $\mathrm{H}$. pylori infection. Considering our relults it reveals that there is much correlation between esophagitis and $\mathrm{H}$. pylori infection.

As considering our findings, we recommend that a combination of RUT with Gram smear and or culture should be performed to diagnose a case of dyspepsia associated with Helicobacter pylori.

\section{Acknowledgement:}

We would like to express our sincere thanks and gratitude to the Regional Medical Research Centre (NE Region), Dibrugarh, Assam, for providing the financial support for the research project.

Funding: Nil,

Conflict of interest: None.

Permission of IRB: Yes

\section{References}

1.Unidentified curved bacilli on gastric epithelium in active chronic gastritis. Lancet. 1983 Jun 4;1(8336):1273-5.

2. Parsonnet J, Friedman GD, Vandersteen DP, Chang Y, Vogelman JH, Orentreich N, Sibley RK. Helicobacter pylori infection and the risk of gastric carcinoma. N Engl J Med. 1991 Oct 17;325(16):1127-31.

3. Nomura A, Stemmermann GN, Chyou PH, Kato I, Perez-Perez GI, Blaser MJ. Helicobacter pylori infection and gastric carcinoma among Japanese Americans in Hawaii. N Engl J Med. 1991 Oct 17;325(16):1132-6.

4. Forman D, Newell DG, Fullerton F, Yarnell JW, Stacey AR, Wald N, Sitas F. Association between infection with Helicobacter pylori and risk of gastric cancer: evidence from a prospective investigation. BMJ. 1991 Jun 1;302(6788):1302-5.

5. Huang JQ, Sridhar S, Chen Y, Hunt RH. Metaanalysis of the relationship between Helicobacter 
pylori seropositivity and gastric cancer. Gastroenterology. 1998 Jun;114(6):1169-79.

6.Nardone G. Compare D. De Colibus P. De Nucci G. Rocco A. Helicobacter pylori and Epigenetic Mechanisms Underlying Gastric Carcinogenesis. Dig Dis. 2007;25:225-229 (DOI:10.1159/000103890)

7. Yuki Obata, Shogo Kikuchi, Hiroto Miwa, Kiyoko Yagyu, Yingsong Lin and Atsushi Ogihara. Diagnostic accuracy of serological kits for Helicobacter pylori infection with the same assay system but different antigens in a Japanese patient population. Journal of Medical Microbiology. 2003;52:889-892 DOI 10.1099/jmm.0.05267-0 $05267 \& 2003$

8. Ohara S, Kato M, Asaka M, Toyota T. Studies of ${ }^{13} \mathrm{C}$ urea breath test for diagnosisof Helicobacter pylori infection in Japan. J Gastroenterol. 1998;33:6-13. 9.

9. Tabata H, Fuchigami T, Kobayashi H, Sakai Y, Nakanishi M, Tomioka K, Nakamura S, Fujishima M. Helicobacter pylori and mucosal atrophy in patients with gastric cancer: a special study regarding the methods for detecting Helicobacter pylori. Dig Dis Sci. 1999 Oct;44(10):2027-34.

10. McQuaid KR, McPhee SJ, and Papadakos M A. Current Medical Diagnosis and Treatment. 49th edition, New York: Mc Graw- Hill. 2010. p.500-597.

11.Sengupta S, Saraswathi K, Varaiya A, De A, Gogate A. Helicobacter pylori in duodenal ulcer disease and its eradication. Indian J Med Microbiol. 2002 JulSep;20(3):163-4.

12. Moss S, Calam J. Helicobacter pylori and peptic ulcers: the present position. Gut. 1992 Mar;33(3):289-92.

13. Borody TJ, Andrews P, Mancuso N, McCauley D, Jankiewicz E, Ferch N, Shortis NP, Brandl S. Helicobacter pylori reinfection rate, in patients with cured duodenal ulcer. Am J Gastroenterol. 1994
Apr;89(4):529-32.

14. U Arora, A Aggarwal, K Singh. Comparative evaluation of conventional methods and elisa based $\mathrm{IgG}$ antibodies detection for diagnosis of helicobacter pylori infection in cases of dyspepsia. Indian $\mathrm{J}$ Med Microbiol 2003; 21(1): 46-48.

15. Sengupta S, Saraswathi K, Varaiya A, De A, Gogate A. Helicobacter pylori in duodenal ulcer disease and its eradication. Indian J Med Microbiol. 2002 JulSep;20(3):163-4.

16. V. Subbukesavraja, K. Balam. Comparitive study of invasive methods for diagnosis of Helicobacter pylori in humans. Int.J.Curr.microbio.App.Sci. 2013; 2(7): 63-68.

17. Prasad KN, Singhal S, Ayyagari A, Sharma S, Dhole TN. Association of Helicobacter pylori in patients of Non ulcer dyspepsia. Indian $\mathrm{J}$ Med Microbiol. 1991;31:415-418.

18. Malik A, Singhal S, Mukharji U. Evaluation of ELISA based antibody test against $\mathrm{H}$. pylori in cases of non ulcer dyspepsia. Indian J Med Microbiol. 1999;17:137-139.

19. Nanivadekar SA, Sawant PD, Saraswathi K, Shroff CP, Bichile LS, Patel HD, Shroff DS. Association of Campylobacter pylori with gastritis, duodenal ulcer and gastric ulcer--a preliminary report of dyspeptic patients. Indian J Gastroenterol. 1988 Jul;7(3):141-2.

20. Karnes WE Jr, Samloff IM, Siurala M, Kekki M, Sipponen P, Kim SW, Walsh JH. Positive serum antibody and negative tissue staining for Helicobacter pylori in subjects with atrophic body gastritis. Gastroenterology. 1991 Jul;101(1):167-74.

21. Iwahi T, Satoh H, Nakao M, Iwasaki T, Yamazaki T, Kubo K, Tamura T, Imada A. Lansoprazole, a novel benzimidazole proton pump inhibitor, and its related compounds have selective activity against Helicobacter pylori. Antimicrob Agents Chemother. 1991,Mar;35(3):490-6.

\section{How to cite this article?}

Singh TSK, Dhakal OP, Gautam D, Khandelwal B, Dhakal Mona, Lepcha OT, Bhandari D, Correlation of Helicobacter pylori infections in patients of dyspepsia with or without ulcer with endoscopic findings: Int J Med Res Rev 2016;4(4):519-524. doi: 10.17511/ijmrr.2016.i04.08. 